\title{
Time to Desaturation Less Than One Minute Predicts the Need for Long-Term Home Oxygen Therapy
}

\author{
Ignacio Garcia-Talavera MD, Alfonso Tauroni MD, Jose Luis Trujillo MD, \\ Ruth Pitti MD, Luisa Eiroa MD, Armando Aguirre-Jaime PhD, \\ Alejandro Sánchez MD, and Juan Abreu MD
}

\begin{abstract}
BACKGROUND: Exercise desaturation in patients with COPD is a pathophysiological phenomenon that is not wholly understood and whose clinical consequences are still unclear. METHODS: Eighty-three patients with moderate to severe COPD and $\mathrm{P}_{\mathrm{aO}_{2}}>60 \mathrm{~mm} \mathrm{Hg}$ who desaturated during the 6-min walk test were followed for 5 years. Forty-eight patients had early desaturation $\left(\mathrm{S}_{\mathrm{pO}_{2}}\right.$ fell below $90 \%$ less than one minute after starting the walk test). Spirometry, blood-gas measurements, and 6-min walk tests were performed every 6 months. We recorded 6-min walk distance, baseline $\mathrm{S}_{\mathrm{pO}_{2}}$, lowest $\mathrm{S}_{\mathrm{pO}_{2}}$, and the time to $\mathrm{S}_{\mathrm{pO}_{2}}<90 \%$. In each control, stable patients with severe hypoxia at rest who required long-term oxygen therapy were identified. RESULTS: Upon completion of the study, $65 \%$ of the early desaturators had developed severe hypoxemia and required long-term home oxygen, versus $11 \%$ in the non-early desaturators $(P<.001)$. CONCLUSIONS: In patients with moderate to severe COPD, desaturation within the first minute of the 6-min walk test predicts the need for long-term home oxygen at 5-year follow-up. Key words: COPD; 6-minute walk test; activities of daily living; oxygen therapy. [Respir Care 2011;56(11):1812-1817. (C) 2011 Daedalus Enterprises]
\end{abstract}

\section{Introduction}

COPD is one of the highest mortality and morbidity diseases in the world. Early diagnosis and smoking cessation are key elements to improve its prognosis. ${ }^{1,2}$ Oxygen therapy improves the survival of patients with chronic respiratory failure, but its value in patients who experience night or exercise desaturation is unclear. ${ }^{3}$

\footnotetext{
Drs Garcia-Talavera, Tauroni, Trujillo, Pitti, and Eiroa are affiliated with Servicio de Neumologia; and Drs Garcia-Talavera and Aguirre-Jaime are affiliated with the Research Unit, Hospital Universitario Nuestra Señora da Candelária, Santa Cruz de Tenerife, Canary Islands, Spain. Dr Sánchez is affiliated with the Respiratory Department, Doctor Negrin Hospital of Gran Canaria, Las Palmas, Canary Islands, Spain. Dr Abreu is affiliated with the Pneumology Department, Canarias University Hospital, Tenerife, Canary Islands, Spain.
}

The authors have disclosed no conflicts of interest.

Correspondence: Ignacio Garcia-Talavera MD, Servicio de Neumologia, Hospital Universitario Nossa Senhora da Candelária, Carretera del Rosario, 14538010 Santa Cruz de Tenerife, Spain. E-mail: igarmark@ gmail.com.

DOI: $10.4187 /$ respcare.01164
The 6-min walk test is used in everyday clinical practice ${ }^{4-7}$ and measures the distance walked during 6 minutes. In a previous study in which we evaluated walk distance and oxygen saturation, we analyzed the walk-distance to $\mathrm{S}_{\mathrm{pO}_{2}}<90 \%$ and time to $\mathrm{S}_{\mathrm{pO}_{2}}<90 \%$, and identified 2 groups of desaturators: early desaturators $\left(\mathrm{S}_{\mathrm{pO}_{2}}\right.$ dropped below $90 \%$ within the first minute of the 6-min walk), and non-early desaturators $\left(\mathrm{S}_{\mathrm{pO}_{2}}\right.$ did not drop below $90 \%$ within the first minute of the 6-min walk). ${ }^{8}$ The early desaturators had greater desaturation during activities of daily living, as measured via 24-hour oximetry. However, the clinical consequences of early desaturation in the 6-min walk test are unknown. Early desaturation may be the consequence of certain pathophysiological features in these patients, such as an abnormal gas exchange that shows up only while exercising. We hypothesized that COPD patients who desaturate early in the 6-min walk test might soon develop severe hypoxia at rest.

\section{Methods}

This study was approved by the institutional review board of Nuestra Señora da Candelária University Hospital, Tenerife, Canary Islands, Spain. 


\section{Time to Desaturation Predicts the Need for Long-Term Home Oxygen}

Table 1. Baseline Characteristics $(n=83)$

\begin{tabular}{lc}
\hline \hline Male/female, no. & $73 / 10$ \\
Age, median (percentiles*), y & $66(51-82)$ \\
$\mathrm{FEV}_{1}(\%$ predicted) & $42 \pm 16$ \\
$\mathrm{P}_{\mathrm{O}_{2}}$ (mm Hg) & $66 \pm 6$ \\
$\mathrm{P}_{\mathrm{CO}_{2}}(\mathrm{~mm} \mathrm{Hg})$ & $44 \pm 6$ \\
6-min walk distance (m) & $420 \pm 118$ \\
Initial $\mathrm{S}_{\mathrm{pO}_{2}}(\%)$ & $93 \pm 2$ \\
Lowest $\mathrm{S}_{\mathrm{pO}_{2}}(\%)$ & $83 \pm 5$ \\
Time to $\mathrm{S}_{\mathrm{pO}_{2}}<90 \%$, median (percentiles*), min & $1: 12(0: 10-4: 30)$ \\
Charlson index, median (percentiles*) & $2(1-5)$ \\
& \\
$*$ 5th and 95th percentiles. & \\
\pm values are mean $\pm \mathrm{SD}$. & \\
\hline
\end{tabular}

\section{Subjects}

One-hundred two COPD patients with effort desaturation took part in the study. They all met the American Thoracic Society criteria: they were all current or former smokers with $\mathrm{FEV}_{1}<80 \%$ of predicted and $\mathrm{FEV}_{1}$ / FVC $<0.70$. None of the participants were on long-term oxygen therapy at inclusion. During the 5-year follow-up, 19 patients dropped out (12 did not want to follow the procedures and 7 moved away), and 83 patients remained in the study until they either died, began long-term oxygen therapy, or completed the study (Table 1). There were significant differences between the patients who dropped out and those who completed the study.

\section{Protocol}

Every 6 months, for 5 years, we conducted a clinical check-up, spirometry, blood-gas measurements, and 6-min walk test. We recorded the date and cause of death and of the beginning of long-term home oxygen therapy. Oxygen therapy requirement was independently determined by the hospital staff, who knew nothing of the patients' early versus non-early desaturator classification. The decision to start oxygen therapy was per the Global Initiative for Chronic Obstructive Lung Disease guidelines: $\mathrm{P}_{\mathrm{aO}_{2}} 55-$ $60 \mathrm{~mm} \mathrm{Hg}$ with cor pulmonale, polycythemia, or arrhythmia.

At baseline each patient performed a 6-min walk test per the American Thoracic Society guidelines, walking in a 30-m hall in silence, without obstacles, with a pulse oximetry probe on the right index finger, stopping for rest if necessary under the technician's supervision, to reach the maximum possible walk distance. ${ }^{5} \mathrm{We}$ recorded baseline $\mathrm{S}_{\mathrm{pO}_{2}}$, lowest $\mathrm{S}_{\mathrm{pO}_{2}}$, walk distance to $\mathrm{S}_{\mathrm{pO}_{2}}<90 \%$, and the time spent walking with $\mathrm{S}_{\mathrm{pO}_{2}}<90 \%$. The 6-min walk test was performed again $30 \mathrm{~min}$ later, and we analyzed the best walk distance. We classified as early desaturators those whose $\mathrm{S}_{\mathrm{pO}_{2}}$ fell below $90 \%$ within the first minute of the walk in both tests, and as non-early desaturators those whose $\mathrm{S}_{\mathrm{pO}_{2}}$ did not fall below $90 \%$ within the first minute of the walk in both tests. The researchers were blinded to the results.

\section{Analysis}

We report the patients' general characteristics as nominal variables and frequencies, ordinal or non-normal-scale variables as the median and 5th and 95th percentiles, and data with a near-normal probability distribution as mean $\pm \mathrm{SD}$. We performed simple comparisons of the early desaturators and non-early desaturators and between the patients who did and did not receive oxygen therapy with the Pearson chi-square test for nominal variables, the Mann-Whitney U test for ordinal and non-normal-scale variables, and the Student $t$ test for normal-scale variables. We used the Kaplan-Meier method and the Mantel-Cox log-rank statistical method to analyze survival and time to beginning of oxygen therapy. We used multivariate binary logistic regression analysis to assess the influence of the variable baseline value on oxygen therapy requirement for the variables that presented a difference as to oxygen therapy and the Wald criterion with backward strategy. All the comparisons were bilateral at a $P \leq .05$, and the calculations were performed with statistics software (SPSS 17.0, SPSS, Chicago, Illinois).

We were able to detect significant differences with a $90 \%$ power in a 2-tailed test at $5 \%$ significance level of at least $25 \%$ excess in oxygen therapy among the early desaturators over a $20 \%$ oxygen therapy expected among the non-early desaturators, or of at least $30 \%$ excess in early desaturators among those who received oxygen therapy over a $30 \%$ expected early desaturators among those who did not receive oxygen therapy.

\section{Results}

All the patients desaturated either before or after the first minute in both 6-min walk tests (ie, they were either early or non-early desaturators). Table 2 compares the early and non-early desaturators. The early desaturators walked farther and desaturated more than the non-early desaturators. Moreover, Figure 1 shows that the early desaturators desaturated more deeply. $\mathrm{P}_{\mathrm{CO}_{2}}$ was slightly lower in the early desaturators than in the non-early desaturators. The early-desaturator group's median age was slightly lower, had more men, and had a somewhat higher $\mathrm{FEV}_{1}$. $\mathrm{P}_{\mathrm{aO}_{2}}$ was lower in the early desaturators, although $\mathrm{S}_{\mathrm{pO}_{2}}$ was not significantly different. The comorbidity index was similar in the groups. Table 3 shows the outcomes at 5-year follow-up. The early desaturators required long-term home oxygen therapy more frequently than did the non-early 


\section{Time to Desaturation Predicts the Need for Long-Term Home Oxygen}

Table 2. Differences Between Early and Non-early Desaturators $(n=83)$

\begin{tabular}{|c|c|c|c|}
\hline & $\begin{array}{c}\text { Early } \\
\text { Desaturators } \\
\text { (no. }=48)\end{array}$ & $\begin{array}{l}\text { Non-early } \\
\text { Desaturators } \\
\text { (no. }=35 \text { ) }\end{array}$ & $P^{*}$ \\
\hline 6-min walk distance $(\mathrm{m})$ & $445 \pm 108$ & $385 \pm 125$ & .02 \\
\hline Time to $\mathrm{S}_{\mathrm{pO}_{2}}<90 \%$, median (percentiles $\dagger$ ), min & $0: 40(0: 06-1: 00)$ & $1: 36(1: 06-5: 15)$ & $<.001$ \\
\hline Lowest $\mathrm{S}_{\mathrm{pO}_{2}}(\%)$ & $81 \pm 6$ & $86 \pm 2$ & $<.001$ \\
\hline Body mass index $\left(\mathrm{kg} / \mathrm{m}^{2}\right)$ & $27.8+47$ & $25.8+43$ & .08 \\
\hline Age, median (percentiles $\dagger$ ), y & $65(47-82)$ & $70(48-84)$ & .18 \\
\hline $\mathrm{FEV}_{1}(\%$ predicted $)$ & $42 \pm 15$ & $41 \pm 15$ & .72 \\
\hline $\mathrm{P}_{\mathrm{O}_{2}}(\mathrm{~mm} \mathrm{Hg})$ & $65 \pm 4$ & $69 \pm 7$ & .008 \\
\hline $\mathrm{P}_{\mathrm{CO}_{2}}(\mathrm{~mm} \mathrm{Hg})$ & $45 \pm 5$ & $43 \pm 5$ & .07 \\
\hline Initial $\mathrm{S}_{\mathrm{pO}_{2}}(\%)$ & $93 \pm 2$ & $94 \pm 2$ & .07 \\
\hline Residual volume/total lung capacity (\% predicted) & $152 \pm 29$ & $151 \pm 29$ & .86 \\
\hline Carbon monoxide transfer coefficient $(\mathrm{mL} / \mathrm{min} / \mathrm{mm} \mathrm{Hg} / \mathrm{L})$ & $72.2 \pm 30$ & $68.6 \pm 29$ & .08 \\
\hline $\begin{array}{l} \pm \text { values are mean } \pm \text { SD. } \\
* \text { Via Pearson chi-square, Fisher exact, Mann-Whitney U, or Student } t \text { test. } \\
\dagger \text { th and } 95 \text { th percentiles. }\end{array}$ & & & \\
\hline
\end{tabular}

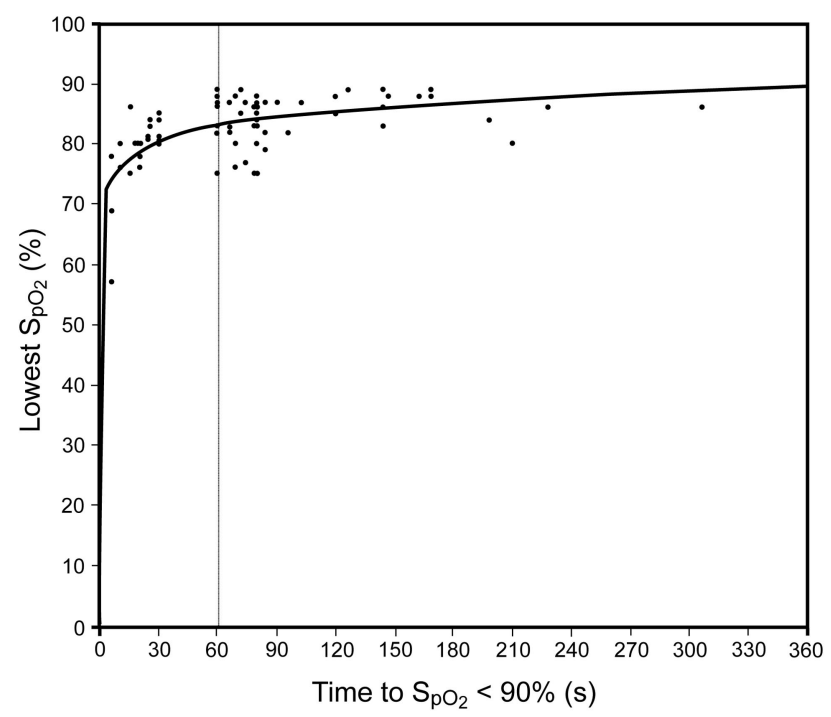

Fig. 1. Lowest $\mathrm{S}_{\mathrm{pO}_{2}}$ versus time to desaturation. The curve that reaches the lower residuals (ie, the absolute sum of the differences between the observed values and the theoretical line followed by these values) is the quadratic one that is represented on the figure.

desaturators. More deaths occurred in the non-early desaturators.

Table 4 shows the differences between those who had and had not started oxygen therapy at 5-year follow-up. $\mathrm{P}_{\mathrm{O}_{2}}$, initial $\mathrm{S}_{\mathrm{pO}_{2}}$, and age were lower in the oxygen group. However, a statistical and clinical difference can be appreciated in the final $\mathrm{S}_{\mathrm{pO}_{2}}$ reached, but it is much lower in the early desaturators. Figure 2 shows the Kaplan-Meier analysis of time to initiation of oxygen therapy. The early desaturators had a much shorter time to oxygen therapy. Figure 3 shows the Kaplan-Meier analysis of survival.
There was a small but significant difference in favor of the non-early desaturators.

Table 5 shows the results of the logistic regression analysis, in which oxygen therapy was the dependent variable, and its possible predictors were early desaturator status, time to $\mathrm{S}_{\mathrm{pO}_{2}}<90 \%$, lowest $\mathrm{S}_{\mathrm{pO}_{2}}$, baseline $\mathrm{P}_{\mathrm{O}_{2}}$, baseline $\mathrm{P}_{\mathrm{CO}_{2}}$, and baseline $\mathrm{S}_{\mathrm{pO}_{2}}$ before the 6-min walk test. Only desaturator status and lowest $\mathrm{S}_{\mathrm{pO}_{2}}$ were marginally significant predictors.

\section{Discussion}

Sixty-five percent of the early desaturators required longterm home oxygen within 5 years, versus only $11 \%$ of the non-early desaturators. The 6-min walk test is a sub-maximal exercise test that depends on ventilatory, cardiovascular, and musculoskeletal capacity and correlates with peak oxygen consumption. ${ }^{9,10} \mathrm{~S}_{\mathrm{pO}_{2}}$ measurements during the 6-min walk test provide additional clinical and prognostic information. Some studies have found that desaturation during the walk test is a factor in poor prognosis. ${ }^{11,12}$ In a previous study we found that early desaturation is more important than non-early desaturation. ${ }^{8}$ The walk time to $\mathrm{S}_{\mathrm{pO}_{2}}<90 \%$ is also valuable information, because early versus non-early desaturation status is prognostic. Early desaturation is associated with substantial desaturation during 24-hour oximetry, which means that early desaturators might desaturate during most of their activities of daily living. ${ }^{8}$ Early desaturation has true clinical importance in that early desaturators are more likely to need long-term home oxygen within 5 years, and therefore have a poorer prognosis. Our early desaturators desaturated more deeply (see Fig. 1), which could be clinically important and should be investigated further. Early desaturation dur- 


\section{Time to Desaturation Predicts the Need for Long-Term Home Oxygen}

Table 3. Outcomes at 5-Year Follow-up $(n=83)$

\begin{tabular}{|c|c|c|c|}
\hline & $\begin{array}{l}\text { Early Desaturators } \\
\quad(\text { no. }=48)\end{array}$ & $\begin{array}{l}\text { Non-early Desaturators } \\
\quad(\text { no. }=35)\end{array}$ & $P^{*}$ \\
\hline Follow-up time, median (percentiles $\dagger$ ), d & $1,137(104-2,220)$ & $2,220(373-2,220)$ & .003 \\
\hline On home oxygen therapy, no. (\%) & $31(65)$ & $4(11)$ & $<.001$ \\
\hline Time to home oxygen therapy, median (percentiles $\dagger$ ), d & $1,078(216-1751)$ & $610(460-763)$ & .25 \\
\hline Deaths, no. (\%) & $12(25)$ & $17(49)$ & .03 \\
\hline Time to death, median (percentiles $\dagger$ ), d & $1,564(104-2150)$ & $1,218(373-2,220)$ & .76 \\
\hline Death rate, median (percentiles $\dagger$ ), deaths/1,000 persons/y & $7.6(5.5-115.3)$ & $13.9(7.6-45.7)$ & .01 \\
\hline
\end{tabular}

* Via Pearson chi-square, Fisher exact, Mann-Whitney U, or Student $t$ test.

$\dagger 5$ th and 95 th percentiles.

Table 4. Differences Between Patients Who Had and Had Not Started Oxygen Therapy at 5-Year Follow-up $(n=83)$

\begin{tabular}{|c|c|c|c|}
\hline & $\begin{array}{l}\text { Had Started } \\
\text { Oxygen Therapy } \\
\text { (no. }=35)\end{array}$ & $\begin{array}{l}\text { Had Not Started } \\
\text { Oxygen Therapy } \\
\quad(\text { no. }=48)\end{array}$ & $P^{*}$ \\
\hline Early desaturators, no. (\%) & $31(89)$ & $17(35)$ & $<.001$ \\
\hline Non-early desaturators, no. (\%) & $4(11)$ & $31(65)$ & $<.001$ \\
\hline Time to $\mathrm{S}_{\mathrm{pO}_{2}}<90 \%$, median (percentiles $\dagger$ ), min:s & $0: 35(0.06-3: 49)$ & $1: 19(0: 18-3: 34)$ & $<.001$ \\
\hline Male/female, no. & $32 / 3$ & $41 / 7$ & .51 \\
\hline Age, median (percentiles $\dagger$ ), y & $64(47-82)$ & $69(51-83)$ & .16 \\
\hline $\mathrm{FEV}_{1}(\%$ predicted $)$ & $40 \pm 14$ & $43 \pm 17$ & .42 \\
\hline $\mathrm{P}_{\mathrm{O}_{2}}(\mathrm{~mm} \mathrm{Hg})$ & $65 \pm 4$ & $68 \pm 7$ & .02 \\
\hline $\mathrm{P}_{\mathrm{CO}_{2}}(\mathrm{~mm} \mathrm{Hg})$ & $45 \pm 5$ & $43 \pm 6$ & .04 \\
\hline 6-min walk distance $(\mathrm{m})$ & $428 \pm 117$ & $415 \pm 121$ & .61 \\
\hline Initial $\mathrm{S}_{\mathrm{pO}_{2}}(\%)$ & $93 \pm 2$ & $94 \pm 2$ & .02 \\
\hline Lowest $\mathrm{S}_{\mathrm{pO}_{2}}(\%)$ & $80 \pm 4$ & $85 \pm 4$ & $<.001$ \\
\hline Charlson index, median (percentiles $\dagger$ ) & $2(1-4)$ & $2(1-5)$ & .36 \\
\hline \multicolumn{4}{|l|}{$\begin{array}{l}\text { * Via Pearson chi-square, Fisher exact, Mann-Whitney U, or Student } t \text { test. } \\
\dagger 5 \text { th and } 95 \text { th percentiles. } \\
\pm \text { values aer mean } \pm \text { SD. }\end{array}$} \\
\hline
\end{tabular}

ing the 6-min walk test is important because it is associated with desaturation during activities of daily living, it predicts the need for long-term home oxygen, and it is accompanied by deep desaturation. The way patients desaturate could thus have important clinical consequences.

The early desaturators were slightly younger, had lower $\mathrm{P}_{\mathrm{O}_{2}}$, and walked farther than the non-early desaturators. Although the age difference between the 2 groups was not statistically significant, the age difference might have influenced the way the patients walked, which might explain the difference in walk distance. We think that these patients present certain pathophysiological features that account for their behavior while exercising. They do not desaturate before other patients because of a lower $\mathrm{P}_{\mathrm{aO}_{2}}$ or arterial saturation. Non-early desaturators desaturate after a few minutes because of certain special intrinsic pathophysiological features that do not depend upon high oxygen pressure or high $\mathrm{S}_{\mathrm{pO}_{2}}$. This is observed on each patient's desaturation curve: the early ones fall suddenly. It

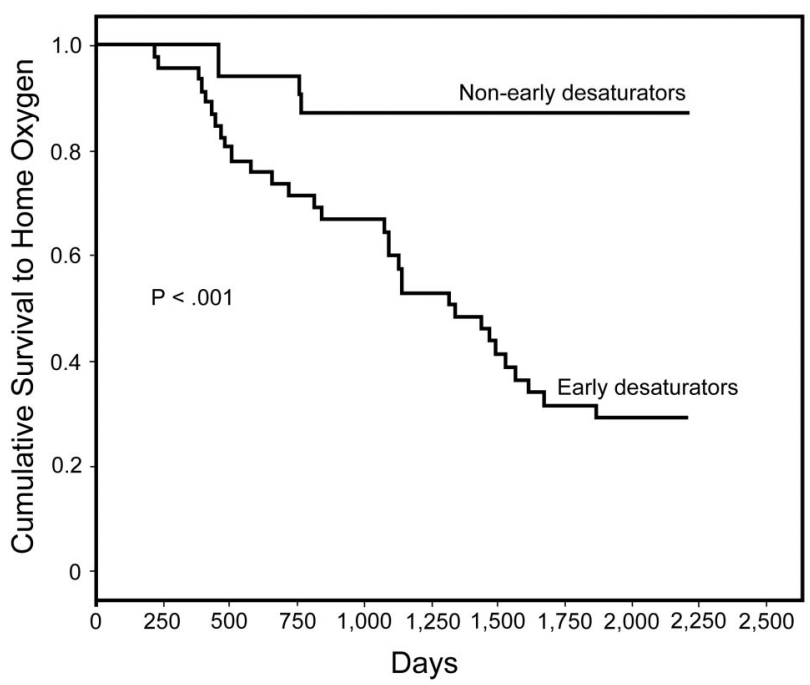

Fig. 2. Kaplan-Meier analysis of time to long-term home oxygen therapy in early desaturators and non-early desaturators in the 6-min walk test. 


\section{Time to Desaturation Predicts the Need for Long-Term Home Oxygen}

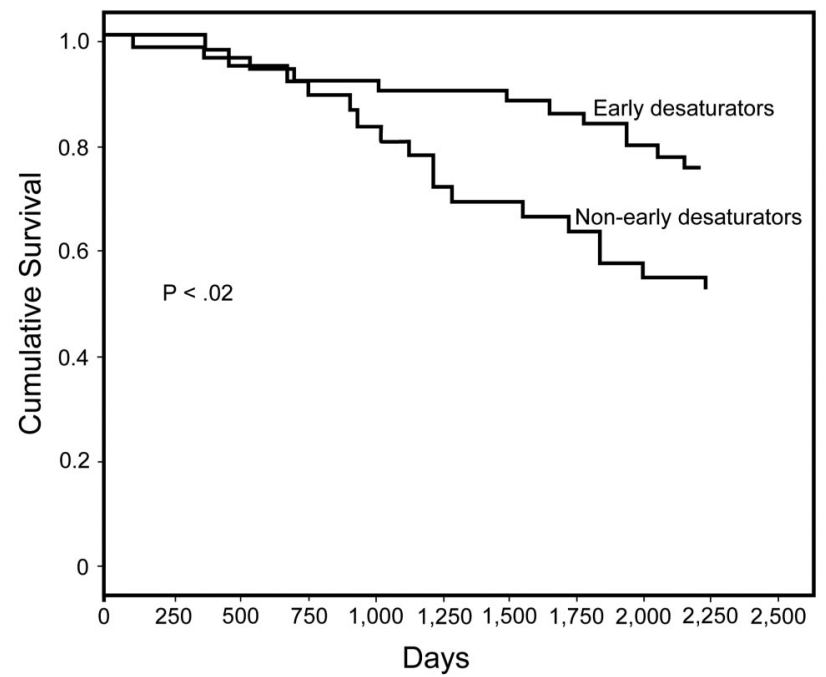

Fig. 3. Kaplan-Meier analysis of survival in early desaturators and non-early desaturators in the 6-min walk test.

Table 5. Multivariate Logistic Regression Analysis of Predictors of the Need for Oxygen Therapy at 5-Year Follow-up

\begin{tabular}{llc}
\hline \hline & $\begin{array}{c}\text { Risk Ratio } \\
(95 \% \mathrm{CI})\end{array}$ & $P$ \\
\hline Early desaturator & $8.7(2.4-30.9)$ & .001 \\
For each $1 \%$ less of lowest $\mathrm{S}_{\mathrm{pO}_{2}}$ & $1.1(1.0-1.2)$ & .050 \\
\hline
\end{tabular}

is very likely that factors such as carbon monoxide diffusion capacity, pulmonary hypertension, or pulmonary mechanics are determinants in early desaturators. However, the groups had similar body mass index, ratio of residual volume to total lung capacity, and carbon monoxide transfer coefficient (diffusion capacity/alveolar volume), although in the early desaturators there was a trend toward greater body mass index $\left(27.8 \pm 47.0 \mathrm{~kg} / \mathrm{m}^{2}\right.$ vs $\left.25.8 \pm 43.0 \mathrm{~kg} / \mathrm{m}^{2}, P=.08\right)$.

Although it was not our objective to analyze the between-group mortality difference, Table 3 shows that mortality was lower among the early desaturators, which might be because they received oxygen therapy, which is known to improve COPD patients' survival. ${ }^{13,14}$ Table 4 shows that more early desaturators received oxygen therapy and those who received oxygen therapy had significantly lower baseline $\mathrm{P}_{\mathrm{O}_{2}}$ and significantly higher $\mathrm{P}_{\mathrm{CO}_{2}}$. Patients with low initial $\mathrm{S}_{\mathrm{pO}_{2}}$ or $\mathrm{P}_{\mathrm{O}_{2}}$ are theoretically more likely to require oxygen because their $\mathrm{S}_{\mathrm{pO}_{2}}$ and $\mathrm{P}_{\mathrm{O}_{2}}$ are nearer the threshold below which long-term home oxygen is prescribed. Our analysis of these 3 variables indicates that early desaturation has the greatest statistical power (see Table 5). Desaturation during the 6-min walk test is thus a key factor, and even more so if desaturation occurs during the first minute of the walk. Oxygen might improve this poor prognosis once the patient suffers from respiratory failure. We do not know, however, what would have happened to mortality had those patients not received oxygen. More importantly, we do not know what would have happened had we initially administered oxygen during exercise when the patients desaturated but did not present respiratory failure. Further study is required to determine whether it is necessary to administer oxygen to patients with mild hypoxemia and early desaturation during the walk test. Some studies have found that, in patients who have only mild or nocturnal hypoxemia, oxygen therapy does not improve survival, ${ }^{3,15}$ quality of life, ${ }^{16}$ or activities of daily living. ${ }^{17}$ By contrast, Eaton et al, who studied patients with COPD and exercise desaturation, found improved quality of life in their patients. ${ }^{18}$ Fujimoto et al, who studied 75 patients with mild to severe COPD and mild hypoxemia, found that their desaturator patients walked farther in the 6-min walk test and had improved pulmonary pressure after administration of oxygen during exercise. ${ }^{19}$ Jolly et al found that their patients, especially the desaturators, walked farther and suffered less dyspnea after oxygen administration. ${ }^{20}$ However, they analyzed the improvement following oxygen therapy in desaturators in general, not in early desaturators, in whom better results might be obtained. Further research is needed on the role of oxygen administration during exercise in early desaturators.

\section{Limitations}

First, there were only 10 female patients, and although these were evenly distributed in the groups, we cannot draw conclusions specifically about women with COPD. Second, the mean initial $\mathrm{P}_{\mathrm{O}_{2}}$ in the early-desaturation group was slightly lower than that in the non-early desaturators, which might have influenced the fact that they reached severe hypoxia earlier. Third, the 6-min walk distance was greater in the early desaturators, which might have affected our results.

As in patients with other pathologies, we think that the 6-min walk test is an effective tool in the clinical management of patients with COPD, to determine walk distance ${ }^{21}$ and $\mathrm{S}_{\mathrm{pO}_{2}}$ changes. ${ }^{22,23}$ The 6-min walk test is a very sensitive test that is used to detect oxygen desaturation ${ }^{24}$ and to determine the oxygen flow necessary to correct exercise-induced desaturation. ${ }^{25}$ Exercise desaturation in patients with emphysema and normoxia at rest has been associated with poor prognosis, although it remains to be seen whether oxygen therapy improves survival in those patients. ${ }^{26}$

\section{Conclusions}

Desaturation that occurs less than 1 min after starting the 6-min walk test in patients with moderate to severe 


\section{Time to Desaturation Predicts the Need for Long-Term Home Oxygen}

COPD and mild hypoxemia is an early sign of future severe chronic hypoxemia. These patients should seek medical treatment and be observed more closely than those without early desaturation. Further research is required to determine the usefulness of oxygen therapy in these patients.

\section{ACKNOWLEDGMENTS}

We are grateful to Françoise Salager-Meyer, Graduate School of Medicine, Universidad de Los Andes, Mérida, Venezuela, for review of the manuscript, and to Angela Montejo and Candelaria González for technical assistance.

\section{REFERENCES}

1. Celli BR, MacNee W; ATS/ERS Task Force. Standards of the diagnosis and treatment of COPD. Eur Respir J 2004;23(6):932-946. Erratum in: Eur Respir J 2006;27(1):242.

2. Pauwels RA, Buist AS, Calverly PM, Jenkins CR, Hurd SS. Global strategy for the diagnosis, management, and prevention of chronic obstructive pulmonary disease Workshop summary. Am J Respir Crit Care Med 2001;163(5):1256-1276.

3. Cranston JM, Crockett AJ, Moss JR, Alpers JH. Domiciliary oxygen for chronic obstructive pulmonary disease. Cochrane Database Syst Rev 2005;19(4): CD001744.

4. Sciurba F, Criner GJ, Lee SM, Mohsenifar Z, Shade D, Silvka W, Wise RA; NETT Research Group, et al. Six-minute walk distance in chronic obstructive pulmonary disease: reproducibility and effect of walking course layout and length. Am J Respir Crit Care Med 2003; 167(11):1522-1527.

5. ATS Committee on Proficiency Standards for Clinical Pulmonary Function Laboratories. ATS statement: guidelines for the six-minute walk test. Am J Respir Crit Care Med 2002;166(1):111-117.

6. -Redelmeier DA, Bayoumi AM, Goldstein RS, Guyatt GH. Interpreting small differences in functional status: the six minute walk test in chronic lung disease patients. Am J Respir Crir Care Med 1997;155(4):1278-1282.

7. Nici L. The mayor limitation to exercise performance in COPD is inadequate energy supply to the respiratory and locomotor muscle vs.lower limb muscle dysfunction vs. dynamic hyperinflation. J Appl Physiol 2008;105(2):760-761.

8. Garcia-Talavera I, Hernández C, Macario C, De Torres JP, Celli BR, Aguirre-Jaime A. Time to desaturation in the 6-min walking distance test predicts 24-hour oximetry in COPD patients with a $\mathrm{PO}_{2}$ between 60 and $70 \mathrm{mmHg}$. Respir Med 2008;102(7):1026-1032.

9. Gosselink R, Troosters T, Decramer M. Peripheral muscle weakness contributes to exercise limitation in COPD. Am J Respir Crit Care Med 1996;153(3):976-980.

10. Troosters T, Vilaro J, Rabinovich R, Casas A, Baebera JA, Rodrigurz-Roisin R, Roca J. Physiological responses to the 6-min walk test in patients with chronic obstructive pulmonary disease. Eur Respir $\mathrm{J}$ 2002;20(3):564-569.

11. Takigawa N, Tada A, Soda Ryo, Date H, Yamashita M, Endo S, et al. Distance and oxygen desaturation in 6-min walk test predict prognosis in COPD patients. Respir Med 2007;101(3):561-567.
12. Casanova C, Cote C, Marín JM, Pinto-Plata V, De Torres JP, Aguirre-Jaime A, Celli BR. Distance and oxygen desaturation Turing the 6-min walk test as predictors of long-term mortality in patients with COPD. Chest 2008;134(4):746-752.

13. Nocturnal Oxygen Therapy Trial Group. Continuous or nocturnal oxygen therapy in hypoxemic chronic obstructive lung disease: a clinical trial. Ann Intern Med 1980;93(3):391-398.

14. Medical Research Council Working Party. Long term domiciliary oxygen therapy in chronic hypoxic cor pulmonale complicating chronic bronchitis and emphysema. Lancet 1981;1(8222):681-686.

15. Gorecka D, Gorzelak K, Sliwinski P, Tobiasz M, Zielinski J. Effect of long-term oxygen therapy on survival in patients with chronic obstructive pulmonary disease with moderate hypoxaemia. Thorax 1997;52(8):674-679.

16. Nonoyama ML, Brooks D, Guyatt GH, Goldstein RS. Effect of oxygen on health quality of life in patients with chronic obstructive pulmonary disease with transient exertional hypoxemia. Am J Respir Crit Care Med 2007;176(4):343-346.

17. McDonald CF, Blyth CM, Lazarus MD, Marschner I, Barter CE. Exertional oxygen of limited benefit in patients with chronic obstructive pulmonary disease and mild hypoxemia. Am J Respir Crit Care Med 1995;152(5 Pt 1):1616-1619.

18. Eaton T, Garret JE, Young P, Fergusson W, Kolbe J, Rudkin S, Whyte K. Ambulatory oxygen improves quality of life of COPD patients: a randomised controlled study. Eur Respir J 2002;20(2): 306-312.

19. Fujimoto K, Matsuzawa Y, Yamaguchi S, Koizumi T, Kubo K. Benefits of oxygen on exercise performance and pulmonary hemodynamics in patients with COPD with mild hypoxemia. Chest 2002; 122(2):457-463.

20. Jolly EC, Di Boscio V, Aguirre L, Luna CM, Berensztein S, Gene RJ. Effects of supplemental oxygen during activity in patients with advanced COPD without severe resting hypoxemia. Chest 2001; 120(2):437-443.

21. Pinto-Plata VM, Cote C, Cabral H, Taylor J, Celli BR. The 6-min walk distance: change over time and value as a predictor of survival in severe COPD. Eur Respir J 2004;23(1):28-33.

22. Paciocco G, Martinez FJ, Bossone E, Pielsticker E, Gillespie B, Rubenfire M. Oxygen desaturation on the six-minute walk test and mortality in untreated primary pulmonary hypertension. Eur Respir J 2001;17(4):647-652

23. Lettieri CJ, Nathan SD, Browning RF, Barnett SD, Ahmad S, Shorr AF. The distance-saturation product predicts mortality in idiopathic pulmonary fibrosis. Respir Med 2006;100(10):1734-1741.

24. Poulain M, Durand F, Palomba B, Ceugniet F, Desplan J, Varray A, Préfaut C. 6-minute walk testing is more sensitive than maximal incremental cycle testing for detecting oxygen desaturation in patients with COPD. Chest 2003;123(5):1401-1407.

25. Morante F, Guell R, Mayos M. [Efficacy of the 6-minute walk test in evaluating ambulatory oxygen therapy]. Arch Bronconeumol 2005; 41(11):596-600. Article in Spanish.

26. Drummond MB, Blackford AL, Benditt JO, Make BJ, Sciurba FC, McCormack MC, et al. Continuous oxygen use in nonhypoxemic emphysema patients identifies a high-risk subset of patients. Retrospective analysis of the National Emphysema Treatment Trial. Chest 2008;134(3):497-506. 